\title{
IDENTIFICAÇÃO DO DIFERENTE: OS POSTS PUBLICITÁRIOS DE LU DO MAGAZINE LUIZA, EM PERSPECTIVA BAKHTINIANA'
}

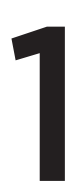

\section{IDENTIFICATION OF THE DIFFERENT:LU'S ADVERTISING POSTS FROM MAGAZINE LUIZA, IN BAKHTINIAN PERSPECTIVE}

\section{CAMARGO, Gabriella Cristina Vaz}

Doutoranda em Linguística e Língua Portuguesa pela UNESP/Araraquara. Bolsista CAPES

E-mail: gabriellavazcamargo@gmail.com

ORCID ID: https://orcid.org/0000-0002-2499-3460

\section{MARCHEZAN, Renata Coelho}

Doutora em Linguística pela Universidade de São Paulo

Docente do PPG Linguística e Língua Portuguesa da UNESP/Araraquara

E-mail: renata_marchezan@uol.com.br

ORCID ID: https://orcid.org/0000-0001-7453-1734

\section{RESUMO:}

O Magazine Luiza, empresa brasileira do ramo de vendas, utiliza, em sua publicidade, o avatar digital Lu, uma personagem virtual 3D, que divulga produtos e interage com os consumidores nas redes sociais. O presente trabalho analisa essa publicidade em que um avatar se apresenta como produtor de enunciados e assume uma identidade própria. Para tanto, fundamenta-se nas proposições teóricas do Círculo de Bakhtin, em especial, no conceito de relação dialógica, que se estabelece entre o eu e o outro nos enunciados. São analisados quatro posts publicitários, de 2019, publicados no Instagram e no Facebook, e os dez primeiros comentários de cada post. Os resultados da análise destacam, nos enunciados, a construção da humanização do avatar, bem como a tentativa de identificação entre Lu e os consumidores, por meio de um estilo afetuoso e coloquial. Lu se aproxima de seus interlocutores, busca estabelecer uma relação de amizade e confiança, e, assim, conquistá-los como clientes. Procura-se, com o estudo, discutir sobre o modo recente de fazer publicidade e vender produtos, que estabelece diálogos "reais", afetuosos e de confiança entre pessoas

$\overline{1}$ O presente trabalho foi realizado com apoio da Coordenação de Aperfeiçoamento de Pessoal de Nível Superior - Brasil (CAPES) - Código de Financiamento 001. 
e avatares. Se, como afirma Bakhtin, a constituição do sujeito se dá na relação com o outro, ela, mais do que nunca, se realiza em ambientes sem fronteiras entre o real e o virtual.

Palavras-chave: Círculo de Bakhtin. Relação eu/outro. Gênero discursivo. Post publicitário.

\section{ABSTRACT:}

The Brazilian company Magazine Luiza uses, in its advertising, the digital avatar Lu, a 3D virtual character, which promotes products and interacts with consumers on social networks. In this work, we analyze that advertising in which an avatar presents itself as a producer of utterances and with its own identity. We base the study on the theoretical propositions of the Bakhtin Circle, especially on the concept of dialogical relationship, which is established between the self and the other in the utterances. We analyzed four advertising posts, from 2019, published on Instagram and Facebook, and the first ten comments of each post. The analysis of the statements shows the construction of the humanization of the avatar and the attempt to identify Lu and the consumers, through an affectionate and colloquial style. Lu gets close to the interlocutors, seeks to establish a relation of friendship and trust, and thus win them over as customers. In this study, we seek to discuss the recent way of advertising and selling products, which establishes "real", affectionate and trusting dialogues between people and avatars. If, as Bakhtin says, the constitution of the subject occurs in the relationship with the other, it, more than ever, takes place in environments without borders between the real and the virtual.

Keywords: The Bakhtin Circle. Self/other relationship. Discursive genre. Advertising post.

Quando nos olhamos, dois diferentes mundos se refletem na pupila dos nossos olhos (BAKHTIN [1924] 2011, p. 21).

\section{INTRODUÇÃO}

O discurso publicitário precisa estar nolugar em que há público, para que possa divulgar-se e exercer sua persuasão. Com o desenvolvimento dos diversos meios de comunicação, novas redes sociais têm surgido e estimulado a interação entre as pessoas. As redes como Youtube, 
Facebook, Instagram, Twitter e os aplicativos de mensagens como o WhatsApp têm, frequentemente, ganhado mais usuários². A publicidade também tem usado essas redes para publicar anúncios, criar perfis, divulgar filmes publicitários com histórias emocionantes ${ }^{3}$, investir no mundo virtual, e, assim, produzir novos tipos e estilos de propaganda. As formas de interação são ampliadas, além de modificarem a conexão entre anunciante e consumidor.

É desse contexto que surge a motivação do presente estudo que busca analisar, com base nas contribuições teóricas e metodológicas do chamado Círculo de Bakhtin, como se estabelecem as relações entre alteridades na publicidade veiculada no ambiente virtual das redes sociais; em outras palavras, busca examinar como a publicidade de uma marca estabelece relação com o outro, o consumidor, nesses contextos e com seus recursos. Um exame preliminar dessa publicidade permite depreender, em parte dela, o propósito de construir, com o consumidor, laços de confiança, lealdade, admiração e até elos de amizade. Se isso já acontecia na publicidade, parece ganhar novos contornos em redes sociais, com os recursos da realidade virtual. Procura-se investigar, então, como as mudanças tecnológicas atuam sobre os indivíduos, a sociedade e sua linguagem. As marcas têm buscado aproximação com seus interlocutores, por meio da utilização de uma linguagem específica, que provoca neles a percepção e a sensação de que são tratados de forma especializada, individuada e humanizada. É o que este estudo se propõe a confirmar.

Para tanto, destaca-se a publicidade do Magazine Luiza (doravante, $\mathrm{ML}$ ), empresa brasileira do ramo de vendas a varejo, que utiliza o avatar digital Lu, como responsável por postagens e perfis em redes sociais. Escolhemos, do ano de 2019, dois posts publicitários de Lu - um publicado no Instagram e outro no Facebook ${ }^{4}$, com as temáticas de Natal e Ano Novo, respectivamente - e os dez primeiros comentários de cada post. Os posts são, portanto, relativos a efemérides importantes em nossa cultura, mas para as primeiras análises, selecionamos, de modo aleatório, dois outros posts, e respectivos comentários, das mesmas redes sociais

\footnotetext{
$2 \quad$ Algumas pesquisas coletam e analisam dados sobre o uso das redes sociais no Brasil, como Ranking das redes sociais: as mais usadas no Brasil e no mundo, insights e materiais gratuitos. Disponível em: https:// resultadosdigitais.com.br/blog/redes-sociais-mais-usadas-no-brasil/, e Quais são as redes sociais mais usadas no Brasil? Disponível em: https://rockcontent.com/blog/redes-sociais-mais-usadas-no-brasil/. Acessos em: 31 jan. 2020.

3 O storytelling, que consiste na técnica de construir uma narrativa interessante e inteligente para emocionar, entreter e persuadir o interlocutor, tem conquistado espaço na área de publicidade e marketing.

$4 \quad$ Escolhemos o material do Facebook e do Instagram, por serem as duas redes sociais em que Lu tem o maior número de seguidores.
} 
e do mesmo ano, que exemplificam o modo como Lu alimenta suas páginas em dias normais.

À luz da perspectiva bakhtiniana, que tem como eixo organizador a concepção dialógica da linguagem, analisamos os quatro posts selecionados para analisar a interação, a relação de alteridade construída entre Lu e seus interlocutores e, desse modo, refletir acerca do discurso publicitário do ML.

\section{DO OBJETO DE ESTUDO: A ATUAÇÃO DE LU DO MAGALU}

O avatar Lu é a personagem central da publicidade do $M L$, aparece tanto em anúncios publicitários, divulgados na mídia ou afixados nas lojas físicas, quanto em perfis e posts nas redes sociais. Além das manifestações verbais, Lu assume também a imagem de uma jovem mulher, representada em um desenho icônico (conforme se vê em figuras incluídas a seguir).

Essa personagem, no entanto, não nasceu nas redes sociais. Uma reportagem ${ }^{5}$ do site Meio \& mensagem - jornal dedicado ao mercado de comunicação brasileiro - recupera um pouco sua história. De acordo com a matéria, o ML criou, em 2005, a Tia Luiza, uma assistente virtual, que existia apenas no site da empresa e tinha a tarefa de auxiliar os clientes em suas compras. Ainda conforme o jornal, em 2009, Lu realizou sua primeira postagem no Blog da Lu, um espaço, no site oficial do $\mathrm{ML}$, destinado a oferecer dicas de manuseio de tecnologias. Com a boa repercussão, Lu começou a realizar também postagens em outro espaço do site, intitulado Portal da Lu, em que o objetivo era explicar as funções, diferenças, vantagens e desvantagens dos produtos. Esse foi, segundo o jornal, o caminho do sucesso e popularização da assistente virtual, cuja imagem migrou para a televisão e, logo, para as redes sociais, em que se apresenta como especialista digital. Seu nome passou a ser Lu, não mais Tia Luiza 6 , e, hoje, possui contas no Facebook, Youtube, Instagram e Twitter.

No ambiente virtual, Lu se dirige a seus interlocutores, mostrandose sempre solícita, promovendo ofertas, sanando dúvidas sobre produtos e auxiliando na realização de compras. Em seu Instagram, de que nos ocupamos aqui, juntamente com o Facebook, Lu se identifica como

\footnotetext{
5 Magazine Luiza: Amazon à brasileira. Disponível em: http://marcas.meioemensagem.com.br/ magazine-luiza/. Acesso 24 jan. 2020. A reportagem não está datada, mas seu texto permite indicar que foi escrita em 2017.

6 Lu deslocou-se, assim, do nome Tia Luiza, que aludia à fundadora da empresa, administrada, atualmente, por sua sobrinha Luiza Helena Trajano Inácio Rodrigues.
} 
Lu do Magalu - dois hipocorísticos que se juntam para reforçar uma aproximação fraterna e amigável -traz uma selfie em sua foto de perfil e se apresenta como "influenciadora virtual 3D", "especialista digital do \#magalu" e "criadora de conteúdo".

O Instagram tem assumido uma vocação, antes predominante no Facebook, de compartilhar momentos de intimidade, informações pessoais e demonstrações de afeto. Essa rede social permite, portanto, dar a Lu uma configuração mais humana. Além de promover o ML, seus posts constroem sua personalidade, reafirmada pela interação com seus interlocutores. São publicações e legendas que revelam também posicionamentos sociais: repúdio à violência doméstica, consciência da necessidade do autoexame para prevenir o câncer de mama, preocupação com o meio ambiente, defesa dos animais, entre outros. Ao mesmo tempo os posts expõem o modo de vida de Lu, seu dia a dia semelhante ao de muitas pessoas, que inclui o trabalho, mas também exercícios na academia, corridas no parque, passeios de bicicleta pela cidade, leituras, cuidados com a pele, etc.

No Facebook, a descrição de sua página traz os dizeres "Seja bemvindo ao perfil oficial do Magazine Luiza! Encontre aqui as melhores ofertas e conte com a Lu para tirar todas as suas dúvidas! \#vemserfeliz". Essa rede social, de modo semelhante ao Instagram, permite ao usuário comentar, curtir e compartilhar posts e também fazer denúncias. A foto da seção perfil é o rosto de Lu e a foto de capa traz escrito MAGALU em cores, predominantemente, azul e branco (cores oficiais da empresa). Na página, são compartilhadas imagens de produtos, links de promoções do site e também posts mais pessoais de Lu, como perguntas sobre tecnologia, votos de boa semana, brincadeiras que convidam à interação; por exemplo, Lu incentiva os seguidores a deixarem comentários sobre imagens suas em diversos lugares ou sobre selfies suas com famosos. Alguns posts publicados no Facebook são repetidos no Instagram, especialmente, aqueles que contêm imagens, pois esta última rede social só permite a publicação de imagens no feed ${ }^{7}$ e no stories ${ }^{8}$.

Pode-se dizer que a personalidade de Lu é construída com seus posts, ou seja, em cada oportunidade, em confissões, jogos e desafios, que propõe, tanto no Facebook quanto no Instagram, ela interage com seus seguidores revelando suas características, especialmente, humanas. Sentimentos como alegria, satisfação, tristeza, orgulho, bem-estar,

$7 \quad$ O "feed de notícias" no Instagram corresponde ao que é chamado de "timeline" no Facebook, ou seja, um lugar, na rede social, em que aparecem os últimos posts de seus seguidores ou amigos.

$8 \quad \mathrm{O}$ "stories" é um tipo de postagem que se mantém on-line por apenas 24 horas. 
repúdio, gratidão, são manifestados verbal e visualmente nos enunciados que veicula. Lu não declara sua idade, mas se apresenta como uma mulher bem-sucedida e com carreira estável, que tem uma postura ética e humana.

Diversos são os comentários dos seguidores de $\mathrm{Lu}$, nas duas redes, que polemizam, curiosos, sobre sua origem, sobre sua existência real ou virtual: um robô ou uma boneca, uma pessoa ou um desenho? Isso, certamente, auxilia na visibilidade da marca e na divulgação da própria $\mathrm{Lu}$, que, além especialista digital do $\mathrm{ML}$, atua também, como mostram suas postagens, na cobertura de lançamentos de outras marcas e posa como modelo de confecções - marcas, confecções, vendidas, obviamente, pelo $\mathrm{ML}^{9}$. Ademais, recebe comentários com reclamações sobre os produtos: alguns clientes realizam compras pelo site do ML e, ao constatarem algum problema com a entrega ou mesmo com o produto, deixam comentários negativos nas redes. O interessante é que as respostas a esses comentários são marcadas por um estilo pessoal e gentil, reforçando a impressão de serem respondidos exclusivamente por Lu, com empatia e interesse em resolver cada problema.

\section{A RELAÇÃO EU/OUTRO NA PERSPECTIVA BAKHTINIANA}

Como já adiantamos, a base teórica da análise da publicidade que propomos aqui se encontra nas contribuições do Círculo de Bakhtin, cujo eixo principal é a concepção dialógica da linguagem. Nesse quadro, portanto, mostram-se fulcrais o conceito de diálogo e a questão da relação eu/outro, que apresentamos a seguir, sempre com atenção ao contexto mais amplo das reflexões bakhtinianas, também considerado. Assim sendo, outras noções teóricas também são referidas ao longo do trabalho, entre elas, a noção de esfera de atividade, gênero do discurso, estilo e, ligada a esta, a de entonação.

Como já é de amplo conhecimento, embora o Círculo e, em especial, Bakhtin tenham se debruçado, principalmente, sobre a literatura, suas formulações ultrapassam este âmbito da cultura. Têm fundamentação filosófica, dirigem, portanto, sua atenção às grandes questões sobre o homem, o mundo em que vive e a cultura que cria. Desse modo, as reflexões bakhtinianas mostram-se adequadas também ao exame da publicidade.

$9 \quad$ Em seu perfil no Instagram, Lu publicou fotos de seu trabalho como modelo para a Colgate, marca de creme dental, Motorola e Samsung, marcas de produtos eletrônicos e Zattini, marca de modo feminina, entre outras marcas, cujos produtos são vendidos no site do ML. 
A afirmação de Bakhtin de que "a língua é dialógica ('meio de comunicação') por natureza" ([1952-1953] 2016, p. 118) evidencia a amplitude da abordagem de suas reflexões. A essa afirmação, podemos somar as palavras de Volóchinov:

Obviamente, o diálogo, no sentido estrito da palavra, é somente uma das formas da interação discursiva, apesar de ser a mais importante. No entanto, o diálogo pode ser compreendido de modo mais amplo não apenas como a comunicação direta em voz alta entre pessoas face a face, mas como qualquer comunicação discursiva, independentemente do tipo. Um livro, ou seja, um discurso verbal impresso também é um elemento da comunicação discursiva. Esse discurso é debatido em um diálogo direto e vivo [...]. Além disso, esse discurso verbal é inevitavelmente orientado para discursos anteriores tanto do próprio autor quanto de outros, realizados na mesma esfera [...] (VOLÓCHINOV, [1929] 2017, p. 219, grifos do autor).

Como deixa claro a citação, o diálogo é considerado tanto no sentido estrito, o diálogo da comunicação face a face, quanto no sentido amplo, aquele presente em qualquer comunicação discursiva. Tanto em "voz alta", quanto em "discurso verbal impresso", reconhece-se o diálogo "direto e vivo", que está orientado por diálogos anteriores e para as futuras respostas que receberá.

Quando menciona o diálogo no sentido amplo, na citação acima, Volóchinov fornece o exemplo de "um livro", o que nos permite lembrar que a reflexão proposta, pelo Círculo, sobre a linguagem é sobre a linguagem efetivamente realizada, e não abstratamente considerada. Daí a postulação do enunciado - conceito definido como a unidade da comunicação verbal, como unidade de análise no domínio bakhtiniano.

Nesse sentido, o enunciado funciona como uma ponte de ligação entre o eu e o outro e, assim sendo, é determinado tanto pelo eu, quanto pelo outro, participantes da interação. É disso que trata Volóchinov, no trecho citado abaixo, em que usa o termo "palavra", mas considerando-a como manifestação concreta em uma dada situação, em outros termos, considerando-a enquanto enunciado.

Ela [a palavra] é determinada tanto por aquele de quem ela procede quando por aquele para quem se dirige. Enquanto palavra, ela é justamente o produto das inter-relações do 
falante com o ouvinte. Toda palavra serve de expressão ao "um" em relação ao "outro". Na palavra, eu dou forma a mim mesmo do ponto de vista do outro e, por fim, da perspectiva da minha coletividade. A palavra é uma ponte que liga o eu ao outro. Ela apoia uma das extremidades em mim e a outra no interlocutor. A palavra é o território comum entre o falante e o interlocutor (VOLÓCHINOV, [1929] 2017, p. 205, grifos do autor).

Volóchinov compreende a palavra como uma parte da realidade material, que se modifica e se transformar em signo carregado de ideologia. Nesse processo, primeiro a palavra se relaciona com o psiquismo, tornando-se uma palavra interior, depois quando retorna ao meio social, como palavra exterior, adquire caráter refratário, permeando diferentes formas de interação. Quando no contexto da realidade concreta, no interior da relação eu/outro, a palavra não é apenas um elemento linguístico, ela assume caráter de enunciado, repleto de vozes e de sentidos valorados.

Os sujeitos falantes, os sujeitos produtores de enunciados verbais e pode-se também incluir os não verbais - habitam a dimensão dialógica, e são, primeira e prioritariamente, distinguidos entre "eu" e "outro". Conforme explica Volóchinov ([1930] 2019b), no texto O que é a linguagem/lingua?, a necessidade da linguagem existe, porque o homem não possui existência isolada, mas apenas coletiva. Para desenvolverse cultural e socialmente, precisa relacionar-se com o outro, com outra comunidade.

No conjunto das obras do Círculo, o outro ocupa, assim, um lugar especial, porque se entende que é na interação com esse outro que se constituem os sujeitos, os signos, os sentidos dos enunciados, a cultura. Só é possível a consciência do eu em relação a quem não é esse eu, ou seja, o outro, aí está a importância da alteridade.

Em Para uma filosofia do ato responsável, Bakhtin ([1924] 2010) já iniciara essas reflexões. Posicionando-se contra o teoricismo, contra a ética formal, traça sua arquitetônica do mundo concreto, alicerçada na relação eu/outro, na relação entre dois centros valorativos, que nunca coincidem totalmente.

No estudo $O$ autor e a personagem na atividade estética, Bakhtin ([1924] 2011) examina e detalha a relação eu/outro, tal como se realiza concretamente na literatura, considerando, principalmente, a relação autor/personagem. Mostra, assim, com base no texto literário, 
que é por meio da relação eu/outro que cada um deles constitui sua identidade. Em função do todo das obras do Círculo e em função de sua perspectiva filosófica, pode-se generalizar: a relação eu/outro, que se dá nas trocas de experiências, nas vivências, nos embates, no contato, na interação, constitui o eu e o outro, altera suas identidades, sentimentos, pensamentos, ideais.

A problematização da relação eu/outro compreende as noções de exterioridade e de excedente de visão. A primeira marca a posição que o eu ocupa em relação ao outro, ou seja, uma posição exterior. Expõe-se, assim, claramente a não coincidência entre eu/outro, que, a despeito da perspectiva espacial adotada, é considerada, por Bakhtin e pelo Círculo, principalmente, em termos axiológicos.

$\mathrm{Na}$ citação que segue, vemos como Bakhtin vincula espaço e axiologia para analisar a perspectiva do autor diante do outro, seu personagem, e para destacar o excedente de visão - a segunda noção mencionada - na criação da forma artística:

O excedente de visão é o broto em que repousa a forma e de onde ela desabrocha como uma flor. Mas para que esse broto efetivamente desabroche na flor da forma concludente, urge que o excedente de minha visão complete o horizonte do outro indivíduo contemplado sem perder a originalidade deste. Eu devo entrar em empatia com esse outro indivíduo, ver axiologicamente o mundo de dentro dele tal qual ele o vê, colocar-me no lugar dele e, depois de ter retornado ao meu lugar, completar o horizonte dele com o excedente de visão que desse meu lugar se descortina fora dele, convertê-lo, criar para ele um ambiente concludente a partir desse excedente da minha visão, do meu conhecimento, da minha vontade e do meu sentimento (BAKHTIN, [1924] 2011, p. 23).

O excedente de visão existe porque o eu situa-se fora do outro, não coincide, axiologicamente, com o outro, e, desse modo, tem do outro uma visão que este não tem de si mesmo. Explica-se, assim, a dependência recíproca entre eu/outro, o caráter social da existência humana, com base na qual se analisa também a obra literária.

Como dissemos anteriormente, é essa relação dialógica entre eu/ outro, sempre manifestada em enunciados, que nos propomos examinar na publicidade do ML, considerando as postagens de Lu nas redes sociais. 
Esse recorte teórico não nos dispensa, como também já afirmamos, de fazer menção a outras noções bakhtinianas, intrinsecamente, relacionadas à de enunciado. É o caso, neste trabalho, dos conceitos de campo (ou esfera) de atividade humana, gênero discursivo, estilo e entonação.

O conceito de enunciado compreende a consideração do momento e do, digamos, chão social em que surge; em outros termos, a consideração da esfera de atividade humana em que ele é produzido: esfera científica, religiosa, familiar, artística, jornalística, publicitária etc. Nas palavras de Bakhtin: "o emprego da língua efetua-se em forma de enunciados (orais e escritos) concretos e únicos, proferidos pelos integrantes desse ou daquele campo de atividade humana" ([1952-1953] 2016, p. 11).

Como a noção de esfera de atividade, a de gênero do discurso também compõe a especificidade do enunciado. Entende-se que todo enunciado vincula-se a um gênero e que cada esfera de atividade humana produz diferentes gêneros. No texto Gêneros do discurso, ao definir e conceituar o gênero, Bakhtin retoma a discussão sobre enunciado e afirma que "[...] cada enunciado particular é individual, mas cada campo de utilização da língua elabora seus tipos relativamente estáveis de enunciados, os quais denominamos gêneros do discurso" ([1952-1953] 2016, p. 12). O gênero é, portanto, uma cristalização de modos de dizer, mas uma cristalização relativa, uma vez que acompanha a dinâmica e a heterogeneidade da sociedade, seu tempo, seus valores.

No caso deste estudo, trata-se, portanto, de não esquecer que os enunciados analisados surgem da esfera publicitária, cujas condições, recursos e objetivos acabam por criar tipos recorrentes de enunciados. Entre eles, o "post", que é nosso objeto aqui.

O detalhamento da noção de gênero, nas obras do Círculo, inclui o conceito de estilo ${ }^{10}$, e, relativo a ele, o de entonação, ambos destacados neste estudo.

Constitutivo do gênero, o estilo ${ }^{11}$ diz respeito à seleção de recursos lexicais, fraseológicos e gramaticais da língua (BAKHTIN, [1952-1953] 2016), que não resulta de hábitos estritamente linguísticos. Os modos de

\footnotetext{
10 Para caracterizar os gêneros, Bakhtin ([1952-1953] 2016) destaca, além do estilo, outros dois elementos do enunciado, o conteúdo e a construção composicional.

11 No conjunto das obras de Bakhtin e do Círculo, a noção de estilo é desenvolvida, especialmente, no campo literário, como nos estudos sobre Dostoiévski (BAKHTIN, [1963] 2015) e sobre Rabelais (BAKHTIN, [1940] 2013). Marxismo e Filosofia da Linguagem (VOLÓCHINOV, [1929] 2017) propõe os conceitos de estilo linear e estilo pictórico, fundados nos modos de transmissão do discurso de outrem. Sobre estilo na perspectiva bakhtiniana, também consultamos Brait (2013), Faraco (2009), Sobral (2009), Fiorin (2016).
} 
dizer são carregados de valores da sociedade, particularmente, da esfera de atividade em que o enunciado é produzido.

Entre os elementos de estilo, a entonação (ou tom) é apontada como uma marca privilegiada de manifestação valorativa, que se pode depreender, inclusive, da linguagem escrita. Entende-se que uma oração - unidade da língua - só adquire aspecto valorativo quando se torna um enunciado e, ao se tornar um enunciado, é pronunciada, produzida, com entonação. Assim, a percepção ou reconstituição da entonação permitem a consideração do "enunciado vivo". Como afirma Volóchinov "a entonação sempre está no limite entre o verbal e o extraverbal, entre $o$ dito e $o$ não dito. Na entonação, a palavra entra em contato direto com a vida" ([1926] 2019a, p. 123, grifos do autor).

A análise do corpus proposto, que apresentamos no próximo tópico, busca considerar a entonação, assim como os demais conceitos apresentados, tendo como foco principal, no entanto, a relação dialógica eu/outro, constitutiva dos enunciados.

\section{A RELAÇÃO EU/OUTRO NAS POSTAGENS DE LU}

Com base nas discussões bakhtinianas sobre a relação eu/outro, constitutiva de todo enunciado, examinamos o corpus, aqui recortado. São enunciados que resultam da relação dialógica estabelecida entre o avatar Lu e seus seguidores nas duas redes sociais, estes que são os consumidores, os clientes do ML. Outra relação eu/outro também se destaca na constituição dos enunciados: trata-se da relação entre o ML e Lu, uma relação de delegação de voz. É desses entrecruzamentos de vozes, e seus valores, que resultam os enunciados. Nos termos já citados de Volóchinov ([1929] 2017), os enunciados são determinados tanto pelo eu, que os produz, quanto pelo outro a quem eles são dirigidos.

Lu se apresenta como uma funcionária do $\mathrm{ML}$, mas não uma funcionária comum, já que se identifica também como um avatar em seus termos, uma "influenciadora virtual 3D". Sua existência está ligada à empresa, como uma garota propaganda e também como uma espécie de porta-voz. Fala pelo ML, o representa. Sua relevância para o ML está, certamente, na relação que ela possibilita com o público, com um número relevante de seguidores nas redes que gerencia. Nesse sentido, a atuação do próprio avatar, em suas postagens, se orienta para obter "resposta" (positiva) do público, constituindo-se, dessa maneira, em relação a esse outro, às suas expectativas.

Nos posts, Lu mostra-se sempre vinculada ao ML: muitas vezes está no ambiente de trabalho, usando uniforme e crachá, mas nem sempre. 
Aparece também em outros espaços, como sua casa, academias, bares, etc. Ela publica anúncios da empresa, divulga e comenta promoções, lançamentos, apresenta produtos e explica sua função ou utilidade, mas também expõe seus próprios gostos, talentos, desejos, posicionamentos, ideias, comportamento. Desse modo, acaba expondo o que seria sua personalidade.

Como mencionamos anteriormente, selecionamos para análise quatro postagens ${ }^{12}$ realizadas em 2019, duas em dias normais e duas em datas festivas. Os dez primeiros comentários dos internautas sobre cada postagem - sempre que chegaram a esse número - foram também considerados na análise. A primeira postagem selecionada foi publicada no dia 22 de agosto, no Instagram:

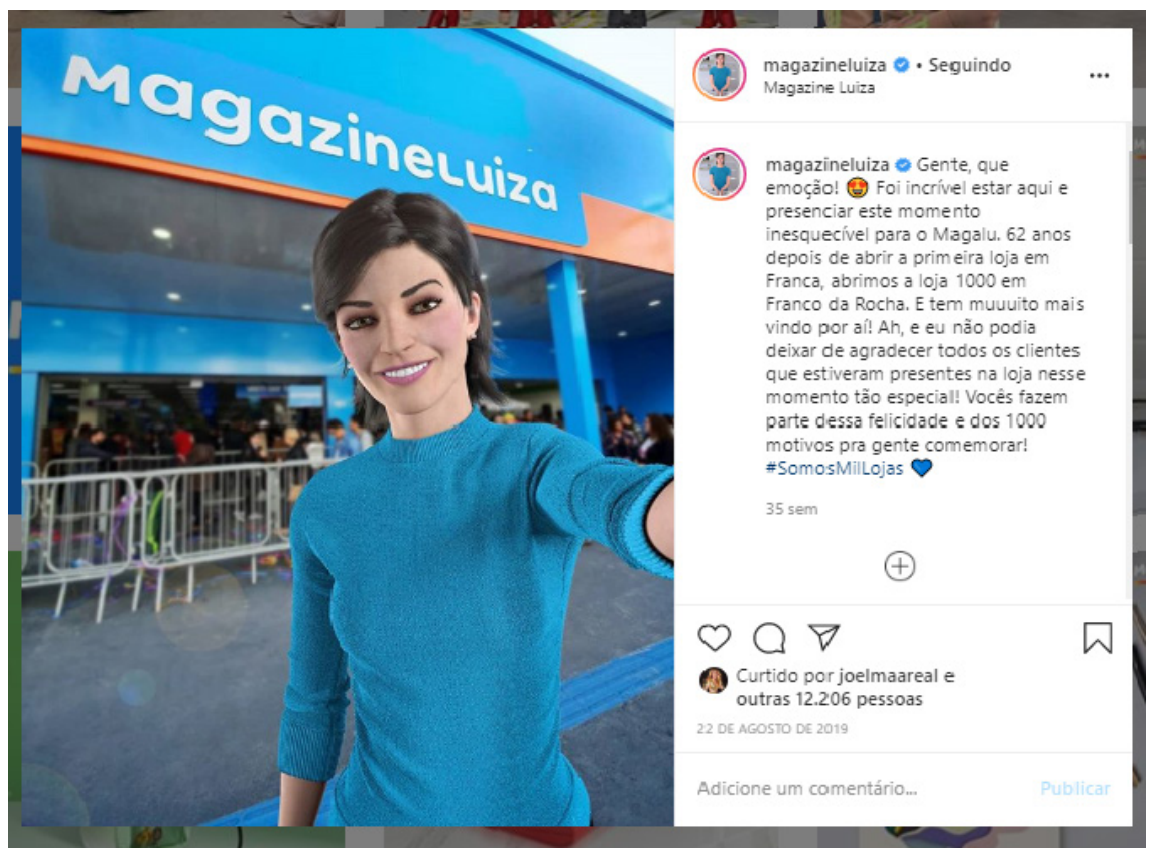

Figura 1: Post publicitário em ambiente de trabalho.

Fonte: Instagram, 2019.

O post traz uma imagem com sua legenda. Lu, em roupa azul, ocupa o centro da imagem, em plano médio e em ângulo quase frontal,

\footnotetext{
12 Todos as postagens que copiamos aqui foram coletadas pelo suporte da tela do computador, com o uso da ferramenta PrintScreen. É importante destacar que a disposição da imagem e da legenda varia de acordo com o suporte (computador, celular, tablete, etc.).
} 
como se ela tivesse tirado uma selfie. Ao fundo, aparece a foto de uma loja física do Magazine Luiza - uma fachada na cor azul e o letreiro da empresa -, com seus clientes. Na imagem, bem montada, é como se Lu estivesse em frente a uma loja física do ML e tirasse uma selfie. Como um flagrante do momento, a imagem quer mesmo servir de registro de um acontecimento, conforme esclarece a legenda, que transcrevemos abaixo para facilitar a leitura ${ }^{13}$ :

Gente, que emoção! Foi incrível estar aqui e presenciar este momento inesquecível para o Magalu. 62 anos depois de abrir a primeira loja em Franca, abrimos a loja 1000 em Franco da Rocha. E tem muuuito mais vindo por aí! Ah, e eu não podia deixar de agradecer todos os clientes que estiveram presentes na loja nesse momento tão especial! Vocês fazem parte dessa felicidade e dos 1000 motivos pra gente comemorar! \#SomosMilLojas.

O acontecimento que a imagem quer registrar, portanto, é a inauguração da milésima loja do ML na cidade de Franco da Rocha, também destacado pela hashtag "SomosMilLojas", incluída ao final da legenda.

A informação da abertura da loja, no entanto, não é divulgada por uma notícia, de modo mais impessoal, mas, sim, obedecendo ao tom pessoal, que é comum nas postagens em rede social, é transmitida em primeira pessoa pela voz da Lu, que dá uma espécie de depoimento emocionado: estava presente no momento da inauguração - "Foi incrível estar aqui e presenciar (...)" -, como comprova também a selfie tirada, e pode contar não tanto o que viu, mas, sim, a emoção que sentiu. Assim, a legenda relata a inauguração, que acaba de acontecer: Lu publica o post, imediatamente, enquanto ainda está no local - "Foi incrível estar aqui". Lu não apenas assistiu à inauguração, mas a vivenciou: mostrase "afetada" pelo acontecimento, expressa um sentimento positivo de "emoção", por presenciar um momento único, especial, a ser comemorado/celebrado. O post manifesta, portanto, que a relação de Lu com o ML não é tão somente profissional, mas também afetiva, e pretende aproximar os seguidores dessa relação afetiva: eles não seriam simples consumidores, mas "parte" da empresa: "Vocês fazem parte dessa felicidade e dos 1000 motivos pra gente comemorar". O "Magalu"

13 Neste trabalho, na transcrição das legendas dos posts, como também dos comentários dos internautas, foram ignorados os emojis. 
agradece o consumidor, deve seu sucesso a eles, que, então, fazem parte dele. Tenta-se estabelecer uma relação de identificação, de aproximação entre $M L$ e o consumidor, mediada pelo gentil avatar.

Como mostram os dez comentários, transcritos no quadro abaixo, o post provoca diferentes "respostas"; todas elas, no entanto, revelam boa aceitação ${ }^{14}$ : manifestações tanto de interesse por lojas da empresa, por produto e por promoção, quanto manifestações de carinho e de admiração. Um dos internautas explicita uma curiosa identificação com a empresa, como se ela, na figura da Lu, fizesse parte de seus desejos ou fantasias: "Meu sonho a lu".

O post, com a imagem e a legenda, é criado seguindo padrões já relativamente assentados, no Instagram e no Facebook, pela própria prática; compreende, pois, nos termos de Bakhtin, citados anteriormente, "tipos relativamente estáveis de enunciados", utilizados nessa esfera particular de utilização da língua, que é a rede social. No caso em análise, vai se configurando um gênero que conjuga post pessoal e publicitário.

Quadro 1: Dez primeiros comentários para o post 1 .

1. [@geissiane_123]: vc existe??

2. [@raphael_noronha04_p]: Meu sonho a lu

3. [@anamaria.sadebrito]: Linda

4. [@blogdamel_rayllabento]: parece uma boneca

5. [@nathalyacomy]: ORGULHO DE SER MIL, ORGULHO DE SER COLABORADORA DESSA LOJA

6. [@bruna.d29dearaujo]: Ainda Tá Tendo A Promoção De Troca De Celular?

7. [@luananaiarachell1]: Vai T Aqui Em Marituba?

8. [@marcialinda8]: Eu queria fazer o cartão da sua loja como faço

9. [@betwolpert]: Meu climatizador chegou. Postei no meus stores... Mandei direct p vcs

10. [@brancaccarvalho]: Ah uma loja dessas aqui em Macapá seria tudo

Fonte: Instagram, 2019

A busca de identificação, que apontamos na análise anterior, entre $\mathrm{ML}$, Lu e o consumidor mostra-se também no segundo post, publicado no Facebook, no dia 23 de outubro de 2019:

14 Parte dos comentários pode, evidentemente, ter sido produzida pelo próprio marketing da empresa, mas essa questão está fora do escopo deste trabalho. 


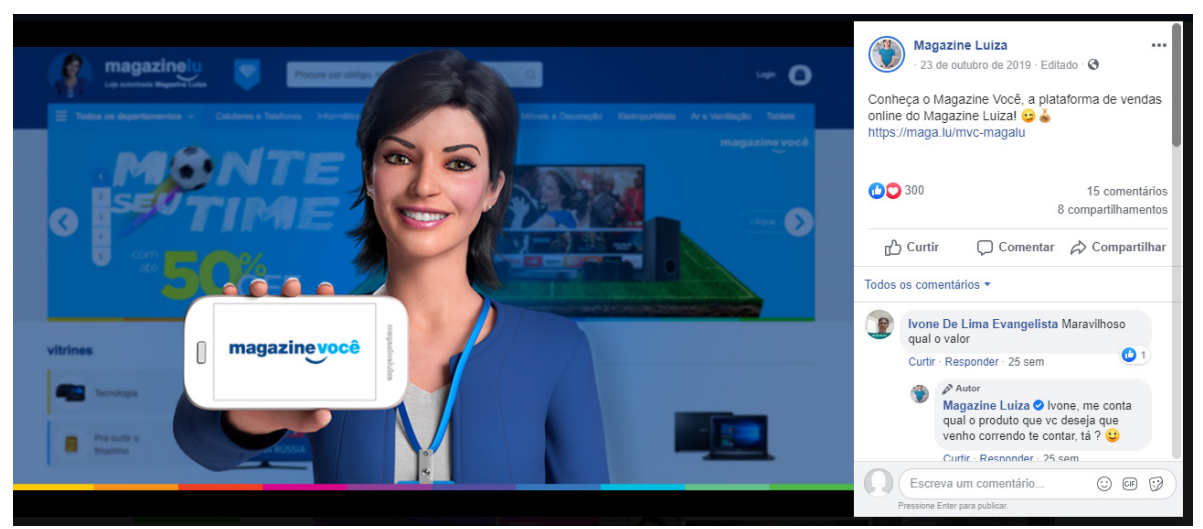

Figura 2: Post publicitário Lu uniformizada.

Fonte: Facebook, 2019.

O post traz uma imagem centralizada e frontal da Lu, em plano médio, tendo como pano de fundo a tela de um computador. Lu estende seu braço direito para frente mostrando a tela do celular que segura, em que aparece a locução: "magazinevocê". À direita, a legenda do post esclarece que se trata da divulgação da plataforma de vendas on-line do ML:

Conheça o Magazine Você, a plataforma de vendas online do Magazine Luiza! https://maga.lu/mvc-magalu.

O nome fantasia da plataforma - "magazinevocê" - presta-se a reforçar a identificação que já apontamos. O nome da empresa é alterado: "Luiza" é substituído pelo dêitico "você", que pode ser preenchido pelo nome de cada possível interlocutor, ou seja, "cada um de vocês que nos segue". Um nome é usado no lugar do outro, como se um nome valesse pelo outro. O nome do consumidor pelo nome da empresa.

A locução magazinevocê permite também ser recebida como uma construção sintática do tipo verbo + objeto, em que o substantivo "magazine" é ressignificado como verbo da primeira conjugação no imperativo, empregado de modo reflexivo, de tal forma que "você" é tanto o sujeito como o objeto direto da ação, conforme é frequente na linguagem coloquial; caso em que "magazinevocê" exorta, à ação de "magazinar-se", aquele a que se dirige. Com a plataforma de compras online, você mesmo se utiliza do Magazine para magazinar-se, em outras palavras, para comprar para si o que o magazine oferece. O substantivo 
que compõe o nome próprio é transformado em verbo, a indicar uma ação que todos podem conjugar.

Os quatro comentários que o post recebeu, incluídos no quadro abaixo, levam a crer que os internautas se detiveram mais na "leitura" da imagem, considerando-a uma divulgação de venda de celular, sem atentarem para a legenda, que divulgava a plataforma de vendas on-line:

\section{Quadro 2: Todos os comentários para o post 4.}

1. [Ivone De Lima Evangelista]: Maravilhoso qual o valor

2. [Maria Rita] Maravilhosos ok

3. [Mheyson Oliveira]: Muito elegante

4. [Fátima Marli DE Paula]: Deve ser muito carro

Fonte: Facebook, 2019.

O terceiro post que analisamos foi publicado na véspera do Natal de 2019, no Instagram no Instagram. Traz uma imagem de Lu, segurando uma grande bola azul com a palavra "gratidão", em frente a uma árvore de natal, cujos enfeites, em sua maioria, são azuis, cor que, novamente, refere ao ML. Embaixo da árvore, há vários presentes, embrulhados também em azul. O ambiente em que Lu está é uma sala de estar; dá para ver janela com cortinas, tapete, luminária e poltrona. Lu não está de azul (afinal, não é dia de trabalho), veste um macacão de cor rosa bebê e sandálias de salto de cor bege; todos esses elementos, somados ao sorriso de Lu e a palavra "gratidão" em destaque, constroem uma ideia de tranquilidade e limpidez. Abaixo, o post publicitário: 


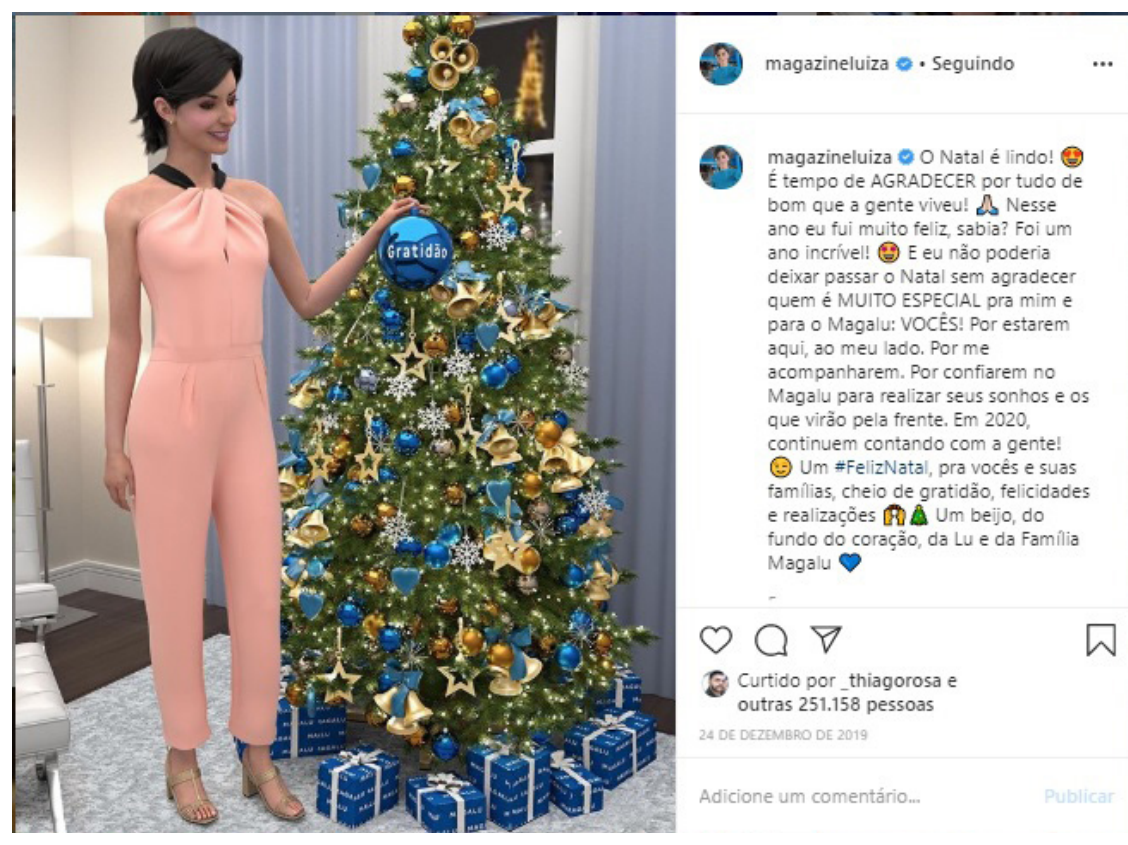

Figura 3: Post publicitбrio de Natal.

Fonte: Instagram, 2020.

A legenda do post aparece ao lado da imagem:

O Natal é lindo! É tempo de AGRADECER por tudo de bom que a gente viveu! Nesse ano eu fui muito feliz, sabia? Foi um ano incrível! E eu não poderia deixar passar o Natal sem agradecer quem é MUITO ESPECIAL pra mim e para o Magalu: VOCÊS! Por estarem aqui, ao meu lado. Por me acompanharem. Por confiarem no Magalu para realizar seus sonhos e os que virão pela frente. Em 2020, continuem contando com a gente! Um \#FelizNatal, pra vocês e suas famílias, cheio de gratidão, felicidades e realizaçãos. Um beijo do fundo do meu coração, da Lu e da Família Magalu.

A atmosfera do Natal, criada na imagem por símbolos da data a árvore enfeitada, os presentes -, é reforçada na legenda: "O Natal é lindo!", "É tempo de AGRADECER (...)!". O dever de agradecer se apresenta como propósito do post. São destacados tanto o objeto do agradecimento quanto seu alvo. O bom ano que termina é o motivo do agradecimento. O post, então, apresenta uma espécie de balanço 
emotivo do ano e o faz usando sempre valorações positivas: "tudo de bom", "muito feliz", "incrível", "realizar (...) sonhos", "gratidão", "felicidades", "realizações". O alvo "especial" do agradecimento é os seguidores, os clientes da empresa, aos quais o post se dirige: "Eu não poderia deixar passar o Natal sem agradecer quem é MUITO ESPECIAL pra mim e para o Magalu: VOCÊS!".

Com o post, o ML transmite, a seus clientes, os votos tradicionais do Natal, mas, delegando voz a Lu, o faz "de pessoa para pessoa", em tom pessoal, emotivo. As relações comerciais empresa/consumidor são traduzidas por relações mais próximas, fraternais, entre iguais. Não se agradece pela preferência na hora da compra, mas pela companhia, pela confiança: "por estarem aqui, ao meu lado. Por me acompanharem. Por confiarem no Magalu para realizar seus sonhos e os que virão pela frente. Em 2020, continuem contando com a gente!". Mais uma vez, os elementos do post, imagem e legenda, reafirmam uma tentativa de identificação entre empresa e consumidor, ambos estão juntos, festejam juntos o sucesso comum.

O post recebe comentários, dez dos quais seguem abaixo:

Quadro 3: Dez primeiros comentários para o post 3.

1. [@silmara.vittar.14] Lu você é muito maravilhosa te amo mt minha virtual preferida!!

2. [@mariannasoares11] Imprensa maravilhosa, amo

3. [@m.a.r.i_a.n.e] Linda

4. [@calbarcellos] ONDE ESTÁ O MEU PRODUTO???? PQ EU PRECISO DE MAIS DOR DE CABEÇA????

5. [@meire.lima.986227] Essa imagem da@magazineluiza eh real ou uma montagem???

6. [@fabiola_silva7] Linda, eu admiro muito.

7.[@jugrasiela01] Amei teu look@maganizeluiza

8. [@marcia_e_fabiano] Meu Deus, efetuei uma compra ontem pelo site da Magalu, e agora só estou vendo reclamação. Arrependida já.

9. [@alice_dantas04] Gataaaaa

10. [@ssgaby6573] Lu vc é real tipo nos que é carne e osso me responde pfv

Fonte: Instagram, 2019.

Dos dez primeiros comentários dos internautas a essa publicação, dois expressam reclamações, um deles inclusive em caixa alta e com vários pontos de interrogação (o que intensifica o tom de questionamento e reprovação); o outro manifesta seu arrependimento por ter realizado compras no site: "onde está o meu produto????"; "pq eu preciso de mais dor de cabeça????"; "agora só estou vendo reclamação"; "arrependida já". 
Os demais comentários mostram uma aproximação afetiva entre Lu e o consumidor, com elogios e manifestação de interesse: "você é muito maravilhosa"; "minha virtual preferia"; "imprensa maravilhosa"; "linda"; "eu admiro muito"; "gataaaaa"; "amei teu look". Também observamos que palavras com conotações afetivas são dirigidas a Lu, como: "te amo mt"; "amo". Alguns internautas questionam se Lu é de verdade ou não: "eh real ou uma montagem?"; "Lu vc é real tipo (...) carne e osso".

O quarto post, publicado na véspera do Ano Novo de 2019, no Facebook, traz também uma imagem de Lu, agora, usando roupa branca, com uma taça na mão direita, sorriso no rosto e o olhar, levemente, direcionado para o alto. Está na calçada da praia de Copacabana, no Rio de Janeiro, e ao fundo o céu indica o início do anoitecer.

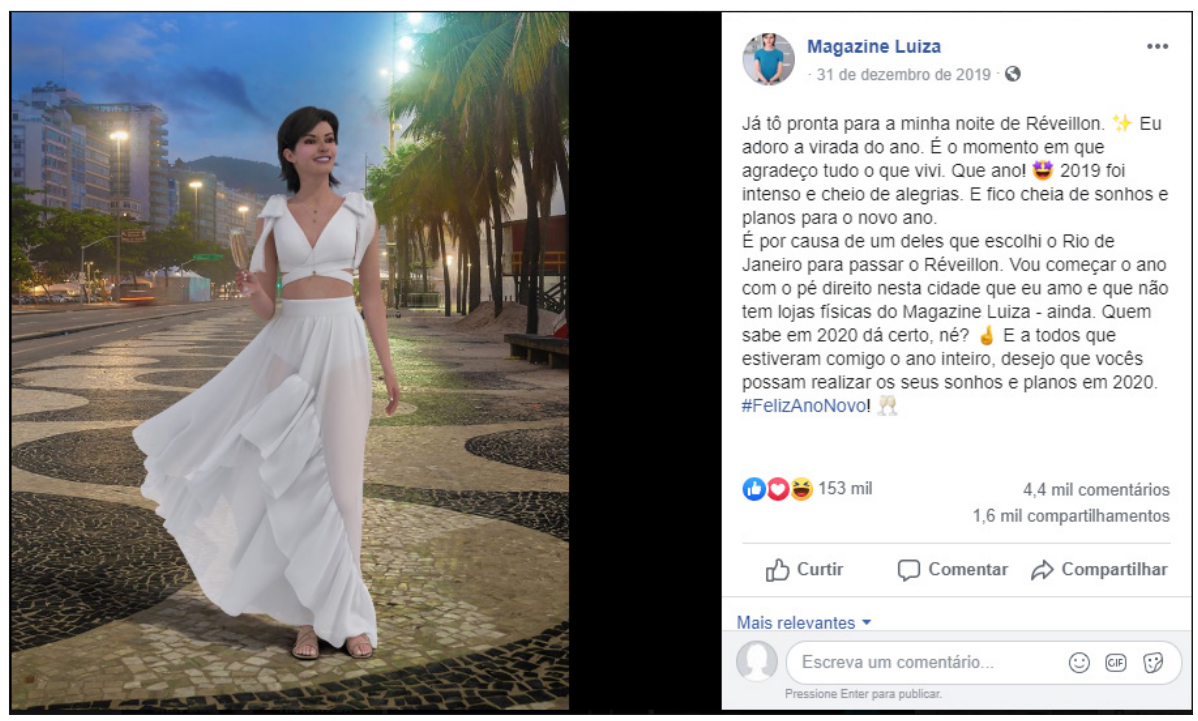

Figura 4: Post publicitário de Ano Novo.

Fonte: Facebook, 2020.

À direita da imagem, aparece a legenda:

Já tô pronta para a minha noite de Réveillon. Eu adoro a virada do ano. É o momento em que agradeço tudo o que vivi. Que ano! 2019 foi intenso e cheio de alegrias. E fico cheia de sonhos e planos para o novo ano. É por causa de um deles que escolhi o Rio de Janeiro para passar o 
Réveillon. Vou começar o ano com o pé direito nesta cidade que eu amo e não tem lojas físicas do Magazine Luiza ainda. Quem sabe em 2020 dá certo, né? E a todos que estiveram comigo o ano inteiro, desejo que vocês possam realizar os seus sonhos e planos em 2020. \#FelizAnoNovo.

Seguindo os padrões do gênero discursivo, o texto da legenda é produzido de tal forma a expressar concomitância entre sua digitalização, o flagrante da imagem e a realização da postagem: "Já tô pronta para a minha noite de Réveillon". Assim como no anterior, nesse post, são retomados discursos sobre o espírito de final de ano. Sentimentos de felicidade, de gratidão, de esperança, retrospectiva positiva, sonhos e planos bons para o ano seguinte são exaltados. Lu destaca que um de seus sonhos era passar o réveillon em Copacabana: "E fico cheia de sonhos e planos para o novo ano. É por causa de um deles que escolhi o Rio de Janeiro para passar o Réveillon". Desse modo, Lu se aproxima de muitos brasileiros que também compartilham desse sonho ${ }^{15}$.

Mesmo nesse momento de festa e de realização de sonho, manifestado tanto na imagem quanto na legenda, Lu não deixa, no entanto, de referir-se ao seu trabalho no ML: "Vou começar o ano com o pé direito nesta cidade que eu amo e não tem lojas físicas do Magazine Luiza - ainda. Quem sabe em 2020 dá certo, né?".

Como também é próprio do gênero, a legenda, juntamente com a imagem, compõe uma conversação, estimula a resposta do outro. Lu dirige-se, explicitamente, a quem a lê, para enviar seus votos de final de ano: "E a todos que estiveram comigo o ano inteiro, desejo que vocês possam realizar os seus sonhos e planos em 2020".

A legenda do quarto post, assim como as demais, é um enunciado em primeira pessoa, é assumido por um "eu" que se dirige a um "você". Trata-se, em termos benvenistianos, das pessoas do discurso, ancoradas, portanto, em um aqui-agora. A voz do eu, assumida por Lu, apresenta um estilo semelhante em todas as legendas analisadas. Bem de acordo com a linguagem comum das redes sociais, as legendas de Lu são produzidas em um estilo bem coloquial, em que predominam o léxico do dia a dia; a sintaxe de períodos simples; as formas reduzidas, como, por exemplo, em " já tô pronta"; a abundância de interjeições e de outros recursos

15 O Réveillon de Copacabana, no Rio de Janeiro, atrai milhões de turistas do Brasil e também do exterior. Historicamente, é conhecido por ter uma das maiores queimas de fogos do mundo. Em 2019, foram esperados mais de 2,8 milhões de pessoas e foi previsto 14 minutos de show de fogos. Disponível em: https:/exame.abril.com.br/estilo-de-vida/ reveillon-em-copacabana-deve-reunir-28-milhoes-de-pessoas/. Acesso em: 06 fev. 2020. 
que expressam uma espécie de grito, como o uso de caixa alta; o uso de hashtags e de emojis, em especial, os que simbolizam agradecimento, benção e emoção; a inserção frequente de pequenas perguntas ao final das frases (question tags), para atrair a participação do interlocutor, conforme "Quem sabe em 2020 dá certo, né?", que aparece na legenda acima; a desconsideração das normas de pontuação da escrita, de modo a simular os recursos rítmicos e melódicos da língua falada.

A esses recursos se junta, como já sublinhamos ao longo deste texto, uma linguagem farta em expressões emotivas e manifestações de sentimento, ao modo mesmo de uma "linguagem direta e espontânea", irrefletida até, como a recriar de maneira viva as emoções. Com apelo ao sensível, mais do que ao inteligível, esse estilo de Lu reforça sua humanidade - não é um robô sem alma, uma entidade programada para vender -, corrobora a aproximação entre ela e os usuários da rede, que parecem se esquecer de sua existência virtual.

O quarto post acima recebe vários comentários. Seguem os dez primeiros:

\section{Quadro 4: Dez primeiros comentários para o post 4.}

1. [Juninho Sant Anna] Que de tudo certo pra você em 2020 Por incrível que pareça nem parece uma loja e sim uma pessoa com sentimentos.

2. [Ana Carolina Rodrigues] Eu também gosto da loja mais fiz uma compra dia 30 do mês passado e a previsão de entrega era 11 dias depois mudou pro dia 27 até então tudo bem mais até agora nada do produto ser entregue

3. [Anadete Ferreira] Vc está linda com essi look

4. [Carla Peixoto] Magalu arrasando parabéns aos responsáveis pela criação da Magalu.

5. [Nel Alegria] Que em 2020 vcs da magazine Luísa venham para o RJ tb; boas vendas, vc está linda

6. [Erotildes Cabral] Linda maravilhosa, feliz ano novo pra vocês também beijaooo.

7. [Thaís Trindade II] Tudo que eu queria, UMA SUPER LOJA da Luiza no RJ, mas não vem me colocar isso na Barra não, coloca em Madureira rsrs

8. [Mara Samantha Vieira] Amei o look vou copiar Lu

9. [Vanessa Nordt da Silva] que linda feliz ano novo

10. [Rose Lins] Queria uma loja no Rio por favor

Fonte: Facebook, 2019.

Dos comentários coletados, apenas um é negativo, traz reclamação da demora na entrega de produto, os demais fazem elogios a Lu e ao Magazine Luiza, com votos de Feliz Ano Novo, elogios à roupa que Lu está vestindo e pedidos para que novas filiais da marca possam ser levadas para o Rio de Janeiro. 
A estratégia da empresa de aproximar-se de seus clientes pela mediação carinhosa e empática de Lu - em termos da retórica, mais pelo "persuadir", do que pelo "convencer" - é, portanto, acolhida, positivamente, pelo internauta. O ML (ou Magalu) e Lu são e não são um só. Pelos posts, sabe-se que Lu trabalha no $\mathrm{ML}$, fala por ele, veste suas cores, se emociona com seu trabalho, etc, mas não se confunde totalmente com a empresa. São duas entidades; ela diz, por exemplo: "pra mim e para o Magalu". Mas fazem parte da mesma "família": "Um beijo, do fundo do coração, da Lu e da Família Magalu". A simbiose entre o Magalu e Lu, no entanto, é tão bem construída que os seguidores acabam por confundi-los como mostra dois comentários acima, que repetimos aqui: "Por incrível que pareça nem parece uma loja e sim uma pessoa com sentimentos"; "Magalu arrasando parabéns aos responsáveis pela criação da Magalu".

\section{CONSIDERAÇÕES FINAIS}

Neste estudo, direcionamos nossa atenção para o discurso publicitário do Magazine Luiza, propagado pelo avatar Lu, no ambiente virtual das redes sociais Instagram e Facebook. Tendo como eixo teórico a relação dialógica entre eu/outro, analisamos quatro posts de Lu e parte dos comentários que receberam. Desse material, "território comum" de diferentes vozes, destacamos a relação que Lu estabelece com os clientes, seus seguidores nas redes. Mas a relação da empresa Magazine Luiza (ou Magalu) e seu avatar também se impôs a nosso exame.

Como vimos anteriormente, Bakhtin privilegia, na análise da forma artística do romance, a relação dialógica que o autor estabelece com o outro, a personagem; e atribui ao modo de o autor operar seu "excedente de visão" desse outro o cerne de sua autoria. No desenvolvimento dessa reflexão, Bakhtin chegará, em outros estudos, às vozes equipolentes do romance, à polifonia. Com base nessa perspectiva teórica, examinamos as relações dialógicas presentes nos enunciados publicitários selecionados. Nesse material, há, obviamente, um trabalho diferente de autoria. Depreendemos dele uma sobreposição de vozes, uma identificação de sujeitos, no que respeita o Magazine Luiza (ou Magalu) e o avatar Lu; e, de modo semelhante, uma aproximação, uma tentativa de identificação entre Lu e seus seguidores. Procedimentos que poderíamos chamar de identificação entre eu/outro, identificação do diferente.

Não é surpreendente a identificação entre o ML e sua criação, e o sucesso da coadjuvante corrobora o mimetismo encontrado na publicidade. ML delega voz a Lu, que declara seu vínculo não apenas 
profissional com a empresa, mas também familiar, afetivo: "a família $M L^{\prime \prime}$.

Com os mesmos laços e valores familiares, de confiança, lealdade, amizade, insistindo em externar "agradecimentos" aos seguidores, os posts de Lu buscam prender os clientes, captar sua empatia e contornar os conflitos, quando aparecem. Os retornos são positivos, na maior parte das vezes.

No Instagram e no Facebook, Lu tem página pessoal, com nome e perfil, em que são publicadas imagens que registram "um momento vivido", "um flagrante notável", acompanhado de uma legenda, uma pequena narrativa em tom pessoal, coloquial e emotivo. O conjunto dos posts analisados permite compor, inclusive, um esboço da personalidade de Lu, seus gostos, sonhos, posicionamentos. Não se trata, pois, de uma propaganda empresarial direta, está traduzida nas regularidades do gênero "post pessoal em redes sociais".

Construídos, portanto, como se fossem "de pessoa para pessoa", os posts acabam por dar corpo a um avatar, acabam por lhe conferir humanidade. A publicidade se faz troca de amabilidades e emoções. A relação eu/outro, na publicidade examinada, é, assim, mais um pequeno evento da relação homem/máquina, um evento a borrar as fronteiras entre o mundo real e o virtual.

\section{REFERÊNCIAS}

AGÊNCIA O GLOBO. Réveillon em Copacabana deve reunir 2,8 milhões de pessoas. Disponível em: <https://exame.abril.com.br/estilo-de-vida/reveillon-em-copacabanadeve-reunir-28-milhoes-de-pessoas/>. Acesso em: 06 fev. 2020.

BAKHTIN, Mikhail. (1952-1953) Os gêneros do discurso. Tradução de Paulo Bezerra. São Paulo: Editora 34, 2016.

BAKHTIN, Mikhail. (1963). Problemas da Poética de Dostoiévski. Tradução de Paulo Bezerra. 5. ed. Rio de Janeiro: Forense Universitária, 2015.

BAKHTIN, Mikhail. (1940). Cultura Popular na Idade Média e no Renascimento: o contexto de François Rabelais. Tradução de Yara Frateschi Vieira. São Paulo: Hucitec, 2013.

BAKHTIN, Mikhail. (1924). O autor e a personagem na atividade estética. In:

Estética da criação verbal (1979). Tradução de Paulo Bezerra. 6.ed. São Paulo: Editora WMF Martins Fontes, 2011, p. 3-192. 
BAKHTIN, Mikhail. (1924). Para uma filosofia do ato responsável. Trad. aos cuidados de Valdemir Miotello e Carlos Alberto Faraco. São Carlos: Pedro \& João Editores, 2010.

BRAIT, Beth. Estilo. In: . (Org.). Bakthin: conceitos-chave. 5. ed. São Paulo: Contexto, 2013, p. 79-102.

COSTA, Thaís. Quais são as redes sociais mais usadas no Brasil? Disponível em: <https:// rockcontent.com/blog/redes-sociais-mais-usadas-no-brasil/>. Acesso em: 31 jan. 2020.

FARACO, Carlos Alberto. Linguagem \& Diálogo: ideias linguísticas do Círculo de Bakhtin. São Paulo: Parábola, 2009.

FIORIN, José Luiz. Introdução ao pensamento de Bakhtin. 2. ed. São Paulo: Editora Contexto, 2016.

IMME, Amanda. Ranking das redes sociais: as mais usadas no Brasil e no mundo, insights e materiais gratuitos. Disponível em: <https://resultadosdigitais.com.br/blog/redessociais-mais-usadas-no-brasil/>. Acesso em: 31 jan. 2020.

MEIO E MENSAGEM. Magazine Luiza: Amazon à brasileira. Disponível em: <http:// marcas.meioemensagem.com.br/magazine-luiza/>. Acesso 24 jan. 2020.

SOBRAL, Adail. Do dialogismo ao gênero: as bases do pensamento do círculo de Bakhtin. Campinas, SP: Mercado de Letras, 2009.

VOLÓCHINOV, Valentin (Círculo de Bakhtin). (1926). A palavra na vida e a palavra na poesia: para uma poética sociológica. In: . A palavra na vida e a palavra na poesia. Ensaios, artigos, resenhas e poemas. Organização, tradução, ensaio introdutório e notas de Sheila Grillo e Ekaterina Vólkova Américo. São Paulo: Editora 34, 2019a. p. 109-146. VOLÓCHINOV, Valentin (Círculo de Bakhtin). (1930). Estilística do discurso literário I: O que é a linguagem/língua? In:

A palavra na vida e a palavra na poesia. Ensaios, artigos, resenhas e poemas. Organização, tradução, ensaio introdutório e notas de Sheila Grillo e Ekaterina Vólkova Américo. São Paulo: Editora 34, 2019b. p. 234-265.

VOLÓCHINOV, Valentin. (1929) Marxismo e Filosofia da Linguagem: Problemas fundamentais do método sociológico na ciência da linguagem. Tradução, notas e glossário de Sheila Grillo e Ekaterina Vólkova Américo. São Paulo: Editora 34, 2017.

Recebido em: 13/05/2020

Aceite em: 15/06/2020 